\title{
Versão brasileira do Defense Style Questionnaire (DSQ) de Michael Bond: problemas e soluções
}

\author{
Mônica Andrade* \\ Itiro Shirakawa**
}

\section{INTRODUÇÃO}

As precárias condições de pesquisa nos chamados países em desenvolvimento, cujos recursos para investimento são sempre muito limitados, têm contribuído para que a prática da tradução e adaptação de instrumentos de avaliação desenvolvidos por pesquisadores de outros países seja relativamente difundida. Além disso, a perspectiva de padronização e ampliação dos universos a serem pesquisados, assim como a busca do enriquecimento propiciado pelos estudos multicêntricos transculturais também incentivam a tradução e adaptação de instrumentos diversos para avaliação em psiquiatria. Isso não significa, entretanto, que as dificuldades desse tipo de procedimento estejam próximas de estar solucionadas. Vários autores têm discutido os

* Doutora, Professora adjunta de Psiquiatria, Departamento de Clínica Médica, Universidade Federal de Uberlândia, Uberlândia, MG

** Doutor, Professor titular de Psiquiatria, Departamento de Psiquiatria, Escola Paulista de Medicina, Universidade Federal de São Paulo (UNIFESP), São Paulo, SP. problemas encontrados durante o processo de tradução e adaptação de instrumentos de avaliação e pesquisa. Questões de natureza cultural, lingüística, gramatical e estatística têm sido apontadas, estudadas e discutidas a partir de diferentes e variados enfoques. Este trabalho tem como objetivo a tradução e adaptação para o português do Defense Style Questionnaire (DSQ), ou Questionário para Estilo de Defesas, desenvolvido por Michael Bond $^{1}$, professor de psiquiatria da McGill University, em Montreal, Canadá. Também será realizado o estudo estatístico da confiabilidade desta tradução para tornar seu uso possível no Brasil.

\section{MATERIAL E MÉTODOS}

\section{O questionário}

O DSQ foi desenvolvido a partir de uma longa linha de pesquisa associada à necessidade de se construir instrumentos que permitissem o estudo experimental ou empírico dos mecanismos de defesa do ego descritos por Sigmund Freud² em 1894. A importância e 
utilidade de tais instrumentos para a clínica têm sido reconhecidas vastamente na literatura psicanalítica e psiquiátrica.

George Vaillant ${ }^{3}$ considera que a mais original contribuição de Freud para a psicologia humana talvez tenha sido sua postulação introdutória de que "mecanismos de defesa inconscientes" protegem o ser humano de emoções, idéias e impulsos dolorosos. Ao descrever a natureza dos mecanismos de defesa do ego, Freud teria estabelecido que os sintomas psicopatológicos se apóiam em afetos e pensamentos perturbadores, mas também observou que grande parte do que é percebido como patológico reflete um processo potencialmente reparador. Esse autor chama a atenção para o fato de que nenhuma observação clínica ou exame psíquico da atualidade podem ser considerados completos sem que se faça uma tentativa de identificar as defesas predominantes do paciente, fundamentais não só para o diagnóstico, como também para qualquer formulação terapêutica.

Michael Bond ${ }^{4}$ observou, entretanto, que a carência de confiabilidade, validade e clareza conceitual para avaliação dos mecanismos de defesa do ego impedia sua adequada mensuração empírica. Em março de 1983, seu grupo de pesquisa apresentou publicação contendo dados que validavam o DSQ desenvolvido, em uma tentativa de eliminar os problemas de avaliação desse construto mencionados acima. Diversos achados comprovaram a validade do instrumento $0^{1,3,4}$. Sua consistência interna fica demonstrada por dois achados experimentais: primeiro, as correlações item/total entre as afirmativas e as defesas que representam foram todas significantes ( $p<0,001)$; segundo, na análise fatorial, a maneira como as defesas se agruparam (clustered) confirma os estudos teóricos já desenvolvidos. Assim, manobras defensivas consideradas imaturas agruparamse no fator 1 ou estilo de defesa 1 (afastamento, regressão, atuação, inibição, agressão passiva e projeção); onipotência, cisão e idealização primitiva agruparam-se no fator 2 ou estilo de defesa 2, representando o estilo chamado de distorção de imagem; formação reativa e pseudo-altruísmo formaram o fator 3 ou estilo de defesa 3 de tipo autosacrifício; finalmente, as defesas consideradas maduras (supressão, sublimação e humor) agruparam-se formando o fator 4 ou estilo de defesa 4. Além disso, o fato de haver uma forte correlação negativa entre as defesas consideradas primitivas e as consideradas de nível mais maduro fornece ainda mais evidências de consistência interna.

Para além do significado e da importância dos mecanismos de defesa do ego, surge ainda a questão da dificuldade de se trabalhar com qualquer fenômeno baseando-se apenas no julgamento clínico.

A necessidade de se estabelecer bases empíricas para identificação e avaliação dos dados em questão é uma premissa básica da pesquisa psicodinâmica moderna.

Diversos autores ${ }^{5-11}$ têm se ocupado em uniformizar conceitos, unificar nomenclaturas e estabelecer as bases teóricas e empíricas para a operacionalização do conceito de defesa psíquica, tornando-o mais adequado para aplicação nos contextos da clínica e da pesquisa.

Partindo do trabalho de George Vaillant, Michael Bond desenvolveu o DSQ, que já vem revelando suas qualidades em aplicações clinicas e de pesquisa ${ }^{7-12}$.

Bond ${ }^{13}$ ressalta vários trabalhos anteriores que tentaram desenvolver métodos experimentais para estudar mecanismos de defesa; entretanto, nenhum deles conseguiu prescindir da participação do julgamento clínico.

Sabendo ser impossível observar diretamente ou medir fenômenos inconscientes, este autor trabalhou com a auto-avaliação de derivados conscientes que, embora não meçam diretamente os mecanismos de defesa, parecem estar relacionados com eles. Lembra ainda que, nesse contexto, o termo "defesa" descreve não só os processos intrapsíquicos inconscientes, mas também comportamentos consciente ou inconscientemente destinados a conciliar impulsos internos e demandas externas. Para sustentar a possibilidade de se autodetectar processos inconscientes, partiuse de dois pressupostos: há momentos em que as defesas falham, podendo-se, então, tomar consciência de impulsos inaceitáveis e de modos habituais de se defender dos mesmos; freqüentemente aponta-se socialmente o modo habitual de funcionamento de uma pessoa.

Sabendo, portanto, da inexistência de um instrumento que prescinda da subjetividade do terapeuta, foi construído um questionário autoaplicável com 88 itens, os quais indicariam derivados conscientes de 24 mecanismos de defesa do ego, revelando estilos defensivos auto-observáveis. Ao completar o teste, os respondentes indicam seu grau de concordância ou discordância com cada item usando uma escala tipo Likert de nove pontos. Todos os itens foram construídos de forma que 
um alto escore indica que o respondente faz uso daquela defesa ${ }^{1,13}$.

Tendo em vista o extenso e rigoroso estudo ao qual $O$ DSQ foi submetido, $1,4,13-15$, consideramos que seria importante, útil e significativo traduzi-lo para o português, principalmente por não dispormos de um instrumento similar nesse idioma. Uma outra questão que nos ocorre é a da pequena tradição de pesquisa empírica dos conceitos psicanalíticos em nosso meio, e a disponibilidade desse instrumento poderia contribuir para o incremento dessa linha de investigações.

Gostaríamos de acrescentar que, após a defesa da dissertação de mestrado ${ }^{16}$ a partir da qual este trabalho foi elaborado, Blaya et al. ${ }^{17}$ repetiram o trabalho de tradução do DSQ para o português, porém dessa vez usaram sua versão reduzida, elaborada por Andrews et al. ${ }^{15}$, e escolheram um enfoque diferente.

\section{A tradução do DSQ}

A metodologia empregada para a tradução do DSQ foi a retrotradução (back-translation), desenvolvida por Werner \& Campbell ${ }^{18}$ e considerada atualmente pela literatura especializada ${ }^{19-25}$ como a mais adequada para buscar um maior grau de equivalência quando comparada, por exemplo, com a tradução direta.

O texto original foi traduzido por três profissionais: dois psiquiatras, sendo um também psicanalista, e um psicólogo; um dos profissionais era bilíngüe* e dois eram altamente proficientes na língua inglesa. Nenhum deles conhecia anteriormente o material a ser traduzido, e nenhuma recomendação prévia foi feita.

Uma versão preliminar desenvolvida pelos tradutores separadamente foi apresentada em uma reunião, na qual foi discutida uma versão consensual. Nessa ocasião, foram utilizadas como subsídios as recomendações e a escala de Brislin ${ }^{19}$ para procedimentos de tradução, e cada item foi avaliado segundo esses critérios.

A versão final foi entregue a dois estadunidenses bilíngües, ambos residentes no

\footnotetext{
* O conceito de bilíngüe em pesquisas transculturais é mencionado por Garyfallos ${ }^{23}$ : pessoa que é fluente em duas línguas e viveu pelo menos 1 ano em cada país, sendo, portanto, bicultural. 0 autor chama a atenção para o fato de que 0 aspecto definidor do conceito deve ser a residência em ambos os países, o que é necessário para que um indivíduo entenda os diferentes significados das palavras e não seja apenas capaz de traduzir
}

Brasil há mais de 20 anos e professores de língua inglesa, que realizaram a retrotradução. As frases resultantes desse processo que refletiram exatamente o original foram imediatamente aceitas. Das 88 afirmativas do questionário, 12 foram consideradas duvidosas e foram rediscutidas com os tradutores e retrotradutores até chegar a novo consenso. Duas das afirmativas continham palavras previsivelmente mais difíceis para bilíngües brasileiros, tendo sido então apresentados o item original e uma versão simplificada do mesmo ${ }^{26}$ :

Item 2: People often call me sulker. (or) People often call me moody.

Item 26: Sometimes when I am not feeling well I am cross. (or) Sometimes when I am not feeling well I get ill humoured.

Terminado o processo, foi realizada nova verificação por um dos tradutores e por ambos os retrotradutores, tendo em vista a noção de que a repetição do processo leva à progressiva melhoria do material ${ }^{20}$. Dessa última revisão, resultou uma pequena modificação em duas das afirmativas, para as quais foram escolhidos novos sinônimos considerados mais adequados ao contexto, embora talvez menos exatos, como, por exemplo, "emburrado", ao invés de "mal humorado", para traduzir sulker e "fico de cara feia" para traduzir I am cross.

\section{Estudo da confiabilidade da versão do DSQ em português}

Para verificar a confiabilidade da tradução do DSQ (versão de 1984), ambas as versões foram aplicadas a 51 sujeitos, sendo 22 bilíngües e 29 fluentes na língua inglesa. Todos eram alunos de três diferentes cursos avançados de inglês, sendo um deles um curso de formação de tradutores e intérpretes. Todos os respondentes foram recrutados mediante solicitação de voluntários em sala de aula.

O procedimento descrito foi proposto por Spielberger et al. ${ }^{21}$ como um meio de testar a fidedignidade de uma tradução e sua equivalência ao instrumento original. A lógica dessa técnica é a de que, se as formas forem equivalentes, sujeitos bilíngües deverão obter aproximadamente os mesmos escores ao responder os testes em português ou em inglês, e as correlações entre os escores obtidos nas duas formas deverá ser alta.

Com o objetivo de afastar as influências da memória, foi respeitado um intervalo de 15 dias entre as duas aplicações, e cada grupo foi subdividido ao meio recebendo as duas versões em ordem alternada. 
Foram levantadas a freqüência, a percentagem de itens não respondidos e a taxa de concordância de respostas iguais emitidas pelos respondentes para cada questão nas duas versões. Essa taxa, expressa em termos de percentagem, poderá ser um indicador do grau de conhecimento da língua inglesa apresentado pelos indivíduos que compõem a amostra, como também pode fornecer indícios de problemas a serem revistos na tradução, uma vez que poderia apontar itens especialmente difíceis para bilíngües brasileiros ${ }^{20,25}$. As taxas de freqüência e concordância entre as versões podem constituir indicadores não só do grau de conhecimento da língua de origem por parte dos respondentes, mas podem também sinalizar problemas a serem melhorados no instrumento traduzido ${ }^{25}$.

Em seguida, foram calculadas as diferenças entre os escores médios obtidos pelos mesmos sujeitos em cada questão, em inglês e em português, e o desvio padrão dessas diferenças. Esses resultados foram analisados em si e através do teste $t$ de Student, que mede a significância estatística das diferenças entre médias de amostras emparelhadas ${ }^{24,25,27}$.

Para verificação da confiabilidade do instrumento traduzido em relação ao seu original, considera-se o cálculo do kappa de Cohen como o mais adequado 22,23,26,28,29. Esse índice de correlação é uma medida percentual de concordância com base estatística e correção para as correlações atribuíveis ao acaso. Foi aplicada a correlação de kappa entre as respostas dadas em inglês e em português para cada questão separadamente. Em seguida, aplicou-se esse mesmo cálculo entre as duas versões para cada sujeito.

A consistência interna do instrumento foi avaliada separadamente para as duas versões através do coeficiente $\alpha$ de Cronbach. "O índice $\alpha$ é uma estimativa de correlação entre duas amostras aleatórias obtidas do universo global de itens de um teste" $23,24,30$.

\section{RESULTADOS}

Dos 51 sujeitos da amostra, havia: 22 bilíngües e 29 fluentes na língua inglesa; 27 mulheres e 24 homens; 23 casados, 24 solteiros, três desquitados e um viúvo; 41 com terceiro grau completo e nove incompleto; um com segundo grau completo e um incompleto. A idade média foi de $30 \pm 8$ anos (em uma faixa de 13 a 54 anos) incompletos.
Inicialmente, foram levantadas a freqüência e a percentagem dos itens não respondidos em cada uma das formas do questionário separadamente e nas duas ao mesmo tempo. A maior percentagem de abstenções ocorreu na forma original do questionário (inglês), sendo que as questões de números 17 e 84 foram responsáveis por 5,88 e 9,80\%, respectivamente. $\mathrm{Na}$ forma traduzida, apenas $\mathrm{O}$ item 84 apresentou mais de uma abstenção (3.92\%).

Foram também levantadas as freqüências e a taxa de concordância entre as respostas emitidas pelos mesmos sujeitos nas duas formas do questionário (Tabela 1). 0 total de respostas iguais foi de 2.508, o que corresponde a 55,88\%. Trabalhamos aqui com duas faixas de concordância: os itens 5, 13 e 81 apresentaram taxas abaixo de $40 \%$ de concordância, enquanto que os itens 60,79 e 85 mostraram concordância acima de $80 \%$.

Foram calculados a média e o desvio padrão dos escores totais de cada item nas duas versões. Foi aplicado o teste de $t$ de Student ( $p<0,001$, bilateral), cujo resultado foi $t=0,91$. Esse valor corresponde a uma probabilidade de 3,4, demonstrando assim ausência de significância estatística entre as diferenças. O intervalo de confiança estabelecido foi de 0,99 (Tabela 2).

Foram ainda avaliadas as correlações entre as respostas para cada item separadamente, em inglês e em português e entre as duas versões para cada sujeito. Foi aplicado o kappa de Cohen (Tabelas 3 e 4). Para as correlações entre os escores de cada questão em português e em inglês, todos os resultados apresentaram significância estatística ( $p<0,001$ - foi usado o teste $z$ para decisão). No caso das correlações entre os escores de cada sujeito em cada uma das línguas, encontramos cinco sujeitos cujos resultados não foram significantes. Todos os demais apresentaram correlações estatisticamente significantes (teste $z ; p<$ 0,001).

A consistência interna foi computada separadamente para as duas versões do DSQ, e os coeficientes $\alpha$ (Cronbach) resultantes foram muito altos e bastante semelhantes: forma original (inglês) $=0,88$; forma traduzida (português) $=0,91$.

\section{DISCUSSÃO}

Sechrest ${ }^{20}$ menciona a necessidade de se cuidar com mais atenção da tradução de 
instruções e comandos, freqüentemente negligenciados no trabalho de tradução de instrumentos de pesquisa. No caso do nosso trabalho, mesmo depois de todo o processo de tradução múltipla, retrotradução, etc., apenas na primeira aplicação verificou-se o engano do autor original, que menciona a suposta existência de uma folha de respostas, quando, na verdade, incluía uma escala para as mesmas logo abaixo de cada questão. Esse duplo engano não só demonstrou a tese de Sechrest, como resultou na necessidade de refazer todo - material a ser aplicado, pois gerou dificuldades de compreensão das instruções.

Outra dificuldade encontrada durante o trabalho de tradução foi a da busca de sinônimos para as palavras associadas à descrição dos sentimentos, estados de ânimo ou afetos em geral. Essas ocorrências ilustram a preocupação de Flaherty ${ }^{22}$, quando lembra que é especialmente difícil a tradução de adjetivos ou termos que descrevem estados emocionais, sendo que uma ampla gama deles estava presente neste questionário. Esse autor também enfatiza, em seu trabalho, a necessidade complexa de se tornar comparável, em cada uma das culturas envolvidas, a descrição de experiências pessoais, freqüentemente encontrada em instrumentos de avaliação psiquiátrica. Comenta que o significado essencial de um termo ou expressão, na maioria das vezes, não pode ser traduzido literalmente, o que torna desejável uma maior flexibilidade na retrotradução. Consideramos que, em nossa experiência, esse problema foi facilitado pelas numerosas discussões entre os tradutores e retrotradutores após a realização da versão inicial. Esse aspecto já havia sido mencionado por de Figueiredo ${ }^{31}$, o qual, revendo a técnica de retrotradução, recomenda que, enquanto a parte inicial do processo deve ser independente e às cegas (tradutores não devem se comunicar em um primeiro momento), a comunicação deve ser intensa e repetida na parte final, associada a consultas a especialistas diversos e de variadas filiações profissionais (por exemplo, psiquiatras, lingüistas, gramáticos, etc.), fazendo-se um verdadeiro "rastreamento" do material.

Ainda outro aspecto que nos chamou a atenção durante as discussões foi o da necessidade de considerar o contexto do significado das afirmativas em contraposição a uma possível tradução mais literal. Houve

Tabela 1 - Freqüência e taxa de concordância entre as respostas emitidas pelos mesmos sujeitos nas duas formas do questionário

\begin{tabular}{lccccc}
\hline Questão & Frq & Taxa & Questão & Frq & Taxa \\
\hline 1 & 24 & 0,47 & 45 & 22 & 0,43 \\
2 & 28 & 0,54 & 46 & 21 & 0,41 \\
3 & 27 & 0,52 & 47 & 30 & 0,59 \\
4 & 29 & 0,56 & 48 & 33 & 0,64 \\
5 & 20 & 0,39 & 49 & 28 & 0,55 \\
6 & 26 & 0,50 & 50 & 34 & 0,66 \\
7 & 28 & 0,54 & 51 & 29 & 0,56 \\
8 & 29 & 0,56 & 52 & 25 & 0,49 \\
9 & 26 & 0,50 & 53 & 29 & 0,56 \\
10 & 26 & 0,50 & 54 & 31 & 0,61 \\
11 & 34 & 0,66 & 55 & 39 & 0,76 \\
12 & 33 & 0,64 & 56 & 24 & 0,47 \\
13 & 17 & 0,33 & 57 & 37 & 0,73 \\
14 & 23 & 0,45 & 58 & 25 & 0,49 \\
15 & 24 & 0,47 & 59 & 22 & 0,43 \\
16 & 31 & 0,61 & 60 & 48 & 0,94 \\
17 & 22 & 0,43 & 61 & 27 & 0,53 \\
18 & 27 & 0,53 & 62 & 27 & 0,53 \\
19 & 33 & 0,64 & 63 & 24 & 0,47 \\
20 & 31 & 0,61 & 64 & 34 & 0,66 \\
21 & 30 & 0,59 & 65 & 29 & 0,56 \\
22 & 25 & 0,49 & 66 & 27 & 0,53 \\
23 & 31 & 0,61 & 67 & 28 & 0,55 \\
\hline
\end{tabular}

\begin{tabular}{cccccc}
\hline Questão & Frq & Taxa & Questão & Frq & Taxa \\
\hline 24 & 26 & 0,50 & 68 & 25 & 0,49 \\
25 & 37 & 0,73 & 69 & 35 & 0,69 \\
26 & 25 & 0,49 & 70 & 37 & 0,73 \\
27 & 27 & 0,53 & 71 & 21 & 0,41 \\
28 & 29 & 0,57 & 72 & 34 & 0,66 \\
29 & 28 & 0,55 & 73 & 26 & 0,50 \\
30 & 27 & 0,53 & 74 & 24 & 0,47 \\
31 & 32 & 0,63 & 75 & 34 & 0,66 \\
32 & 26 & 0,50 & 76 & 23 & 0,45 \\
33 & 27 & 0,53 & 77 & 23 & 0,45 \\
34 & 32 & 0,63 & 78 & 27 & 0,53 \\
35 & 26 & 0,50 & 79 & 42 & 0,83 \\
36 & 23 & 0,45 & 80 & 21 & 0,41 \\
37 & 28 & 0,55 & 81 & 19 & 0,37 \\
38 & 30 & 0,59 & 82 & 30 & 0,59 \\
39 & 33 & 0,64 & 83 & 24 & 0,47 \\
40 & 30 & 0,59 & 84 & 24 & 0,47 \\
41 & 27 & 0,53 & 85 & 47 & 0,92 \\
42 & 36 & 0,70 & 86 & 26 & 0,50 \\
43 & 27 & 0,53 & 87 & 34 & 0,66 \\
44 & 34 & 0,66 & 88 & 25 & 0,49 \\
\multicolumn{2}{r}{ Total = 2.508} & & $2.508 / 448=55,88 \%$ \\
\hline
\end{tabular}


consenso entre os profissionais que trabalharam neste estudo de que o contexto se fazia mais importante na maioria dos casos, mesmo quando poderia haver perdas na precisão da tradução. Werner \& Campbell ${ }^{18}$, idealizadores da técnica de retrotradução, criaram também a noção de "descentralização", que preconiza que ambas as versões (fonte e alvo) sejam consideradas igualmente importantes na preparação da tradução; portanto, se necessário, deve-se alterar a forma da língua original em prol da clareza do significado na língua-alvo. Esse cuidado caracteriza uma diferenciação entre tradução

Tabela 2 - Diferença entre as médias dos escores de cada versão e desvio padrão correspondente

\begin{tabular}{|c|c|c|c|c|c|}
\hline Item & $\begin{array}{l}\text { Média } \\
\text { (P) }\end{array}$ & $D P$ & $\begin{array}{l}\text { Média } \\
\text { (I) }\end{array}$ & $D P$ & Diferença \\
\hline 1 & 6,47 & 2,25 & 6,14 & 2,09 & 0,33 \\
\hline 2 & 3,16 & 2,25 & 3,02 & 2,31 & 0,14 \\
\hline 3 & 4,76 & 2,61 & 5,04 & 2,69 & 0,28 \\
\hline 4 & 2,84 & 2,00 & 2,76 & 1,93 & 0,08 \\
\hline 5 & 4,58 & 2,28 & 4,76 & 2,54 & 0,18 \\
\hline 6 & 6,06 & 2,48 & 5,96 & 2,24 & 0,10 \\
\hline 7 & 4,27 & 2,75 & 4,31 & 2,74 & 0,04 \\
\hline 8 & 5,29 & 2,59 & 4,92 & 2,63 & 0,37 \\
\hline 9 & 4,21 & 2,31 & 4,66 & 2,62 & 0,45 \\
\hline 10 & 5,27 & 2,35 & 4,98 & 2,48 & 0,29 \\
\hline 11 & 3,06 & 2,15 & 3,51 & 2,20 & 0,45 \\
\hline 12 & 2,12 & 1,66 & 2,45 & 1,98 & 0,33 \\
\hline 13 & 4,23 & 2,20 & 4,24 & 2,51 & 0,01 \\
\hline 14 & 4,65 & 2,57 & 5,00 & 2,23 & 0,35 \\
\hline 15 & 5,96 & 2,63 & 5,66 & 2,68 & 0,30 \\
\hline 16 & 2,84 & 2,12 & 3,09 & 2,11 & 0,25 \\
\hline 17 & 2,76 & 2,16 & 3,51 & 2,56 & 0,75 \\
\hline 18 & 3,43 & 2,19 & 3,37 & 2,24 & 0,06 \\
\hline 19 & 2,22 & 1,93 & 2,29 & 1,97 & 0,27 \\
\hline 20 & 7,47 & 1,92 & 7,43 & 1,98 & 0,04 \\
\hline 21 & 4,92 & 2,36 & 5,17 & 2,08 & 0,25 \\
\hline 22 & 3,18 & 2,32 & 3,82 & 2,40 & 0,64 \\
\hline 23 & 2,02 & 1,60 & 2,19 & 1,79 & 0,17 \\
\hline 24 & 3,08 & 1,83 & 2,61 & 1,82 & 0,47 \\
\hline 25 & 2,14 & 1,95 & 2,10 & 1,85 & 0,04 \\
\hline 26 & 6,76 & 1,76 & 6,18 & 1,95 & 0,58 \\
\hline 27 & 5,35 & 2,10 & 4,78 & 2,27 & 0,57 \\
\hline 28 & 4,49 & 2,62 & 4,08 & 2,72 & 0,41 \\
\hline 29 & 4,35 & 2,78 & 4,20 & 2,54 & 0,15 \\
\hline 30 & 3,14 & 2,51 & 3,73 & 2,62 & 0,59 \\
\hline 31 & 4,24 & 2,45 & 3,86 & 2,40 & 0,38 \\
\hline 32 & 6,06 & 2,57 & 6,04 & 2,53 & 0,02 \\
\hline 33 & 3,12 & 2,17 & 3,72 & 2,38 & 0,60 \\
\hline 34 & 2,57 & 2,26 & 3,02 & 2,45 & 0,45 \\
\hline 35 & 5,82 & 2,24 & 5,92 & 1,94 & 0,10 \\
\hline 36 & 5,41 & 2,34 & 5,35 & 2,38 & 0,06 \\
\hline 37 & 4,06 & 2,49 & 4,55 & 2,59 & 0,49 \\
\hline 38 & 4,74 & 2,98 & 4,14 & 2,90 & 0,60 \\
\hline 39 & 3,72 & 2,88 & 3,53 & 2,77 & 0,19 \\
\hline 40 & 4,04 & 2,74 & 3,78 & 2,52 & 0,26 \\
\hline 41 & 4,29 & 2,71 & 4,88 & 2,48 & 0,59 \\
\hline 42 & 2,24 & 1,98 & 2,16 & 1,78 & 0,08 \\
\hline 43 & 4,31 & 2,43 & 4,75 & 2,28 & 0,44 \\
\hline 44 & 7,41 & 2,32 & 7,12 & 2,52 & 0,29 \\
\hline
\end{tabular}

\begin{tabular}{lccccc}
\hline Item & $\begin{array}{c}\text { Média } \\
\text { (P) }\end{array}$ & DP & $\begin{array}{c}\text { Média } \\
(\mathbf{I})\end{array}$ & DP & Diferença \\
\hline 45 & 4,74 & 2,24 & 4,78 & 2,45 & 0,04 \\
46 & 4,27 & 2,24 & 4,70 & 2,27 & 0,43 \\
47 & 2,96 & 1,99 & 3,25 & 2,08 & 0,29 \\
48 & 7,76 & 2,29 & 7,49 & 2,30 & 0,27 \\
49 & 5,78 & 2,55 & 6,20 & 2,13 & 0,42 \\
50 & 4,66 & 2,27 & 4,76 & 2,03 & 0,10 \\
51 & 3,78 & 2,51 & 3,51 & 2,18 & 0,27 \\
52 & 3,78 & 2,49 & 3,73 & 2,58 & 0,05 \\
53 & 3,25 & 2,66 & 3,59 & 2,65 & 0,34 \\
54 & 2,47 & 2,08 & 2,63 & 2,22 & 0,16 \\
55 & 1,88 & 1,87 & 2,12 & 2,04 & 0,24 \\
56 & 5,14 & 2,34 & 4,90 & 2,52 & 0,24 \\
57 & 8,22 & 1,64 & 8,04 & 1,67 & 0,18 \\
58 & 4,47 & 2,92 & 4,37 & 3,06 & 0,10 \\
59 & 5,76 & 2,71 & 5,43 & 2,70 & 0,33 \\
60 & 1,47 & 1,54 & 1,59 & 1,86 & 0,12 \\
61 & 5,67 & 2,15 & 5,35 & 2,32 & 0,32 \\
62 & 4,92 & 2,58 & 3,86 & 2,54 & 1,06 \\
63 & 5,47 & 2,24 & 5,00 & 2,42 & 0,47 \\
64 & 1,98 & 1,64 & 2,22 & 1,86 & 0,24 \\
65 & 3,76 & 2,68 & 3,49 & 2,53 & 0,27 \\
66 & 2,78 & 2,42 & 3,22 & 2,25 & 0,44 \\
67 & 4,24 & 2,54 & 4,33 & 2,53 & 0,09 \\
68 & 7,52 & 1,89 & 7,02 & 2,02 & 0,50 \\
69 & 2,58 & 1,92 & 2,68 & 2,01 & 0,10 \\
70 & 2,33 & 2,27 & 2,31 & 1,98 & 0,02 \\
71 & 4,43 & 2,65 & 4,06 & 2,24 & 0,37 \\
72 & 2,29 & 1,80 & 2,80 & 2,04 & 0,51 \\
73 & 3,88 & 2,41 & 3,75 & 2,44 & 0,13 \\
74 & 5,80 & 2,47 & 5,43 & 2,30 & 0,37 \\
75 & 3,33 & 2,29 & 3,16 & 2,18 & 0,17 \\
76 & 5,35 & 2,52 & 4,88 & 2,52 & 0,47 \\
77 & 3,76 & 2,20 & 4,02 & 2,29 & 0,26 \\
78 & 3,43 & 2,59 & 3,16 & 2,55 & 0,27 \\
79 & 2,20 & 2,17 & 2,37 & 2,44 & 0,17 \\
80 & 5,90 & 2,67 & 5,14 & 2,76 & 0,76 \\
81 & 5,00 & 2,58 & 5,06 & 2,50 & 0,06 \\
82 & 3,53 & 2,22 & 3,82 & 2,34 & 0,29 \\
83 & 3,10 & 1,88 & 3,68 & 2,11 & 0,58 \\
84 & 5,49 & 2,56 & 5,08 & 2,68 & 0,41 \\
85 & 2,63 & 2,98 & 2,60 & 2,95 & 0,03 \\
86 & 4,84 & 2,53 & 4,06 & 2,68 & 0,78 \\
87 & 2,35 & 1,90 & 2,80 & 2,13 & 0,45 \\
88 & 4,37 & 2,78 & 4,41 & 2,73 & 0,04 \\
\hline & & & & &
\end{tabular}

$D P=$ desvio padrão; $I=$ inglês; $P=$ português .

Teste $t$ de Student $(p>001$, bilateral $)=0,23(t=3,46)$. 
literal ou lingüística e tradução cultural, possibilitando a somatória de ambas. É o que também recomenda Berkanovic ${ }^{32}$, ao afirmar que se deve tomar extremo cuidado no sentido de assegurar que qualquer tradução, culturalmente específica ou não, atinja um nível de uso lingüístico equivalente ao da línguafonte, mesmo que com algum prejuízo da forma.

Esse aspecto foi ilustrado, em nossa experiência com o processo de tradução,

Tabela 3 - Coeficiente de correlação de Cohen (kappa)* para escores item por item nas duas versões do Defense Style Questionnaire

\begin{tabular}{|c|c|c|c|}
\hline Item & $K w^{4 *}$ & SE (Kw1) & $z$ \\
\hline 1 & 0,7468 & 0,08532 & 8,75 \\
\hline 2 & 0,6297 & 0,11374 & 5,53 \\
\hline 3 & 0,8044 & 0,06590 & 12,20 \\
\hline 4 & 0,7438 & 0,11481 & 6,47 \\
\hline 5 & 0,4223 & 0,13361 & 3,16 \\
\hline 6 & 0,6686 & 0,10200 & 6,55 \\
\hline 7 & 0,7204 & 0,08123 & 8,86 \\
\hline 8 & 0,7768 & 0,07869 & 9,87 \\
\hline 9 & 0,8952 & 0,03668 & 24,40 \\
\hline 10 & 0,6997 & 0,09209 & 7,59 \\
\hline 11 & 0,7686 & 0,06460 & 11,89 \\
\hline 12 & $\star * *$ & & \\
\hline 13 & 0,6284 & 0,10884 & 5,77 \\
\hline 14 & 0,4436 & 0,16644 & 2,66 \\
\hline 15 & 0,6705 & 0,10440 & 6,42 \\
\hline 16 & 0,4817 & 0,13297 & 3,32 \\
\hline 17 & 0,6119 & 0,15555 & 3,93 \\
\hline 18 & $* \star *$ & & \\
\hline 19 & 0,6682 & 0,10547 & 6,33 \\
\hline 20 & 0,8324 & 0,05430 & 15,32 \\
\hline 21 & 0,7135 & 0,11679 & 6,10 \\
\hline 22 & 0,6026 & 0,12687 & 4,74 \\
\hline 23 & 0,5268 & 0,13784 & 3,82 \\
\hline 24 & 0,7513 & 0,09769 & 7,69 \\
\hline 25 & 0,6731 & 0,16894 & 3,98 \\
\hline 26 & 0,7708 & 0,06693 & 11,51 \\
\hline 27 & 0,8035 & 0,06426 & 12,50 \\
\hline 28 & 0,5811 & 0,10808 & 5,37 \\
\hline 29 & 0,5142 & 0,13562 & 3,79 \\
\hline 30 & 0,6278 & 0,11972 & 5,24 \\
\hline 31 & 0,7134 & 0,10962 & 6,51 \\
\hline 32 & 0,7510 & 0,08648 & 8,64 \\
\hline 33 & 0,4179 & 0,17292 & 2,42 \\
\hline 34 & 0,6565 & 0,09912 & 6,62 \\
\hline 35 & 0,7378 & 0,06605 & 11,17 \\
\hline 36 & 0,8279 & 0,06517 & 12,70 \\
\hline 37 & 0,7498 & 0,07862 & 9.53 \\
\hline 38 & 0,6147 & 0,11547 & 5,32 \\
\hline 39 & 0,7476 & 0,07120 & 10,50 \\
\hline 40 & 0,7334 & 0,09524 & 7,70 \\
\hline 41 & 0,6821 & 0,17601 & 3,87 \\
\hline 42 & 0,6313 & 0,10605 & 5,95 \\
\hline 43 & 0,5076 & 0,13983 & 3,63 \\
\hline 44 & 0,5365 & 0,13452 & 3,98 \\
\hline
\end{tabular}

\begin{tabular}{|c|c|c|c|}
\hline Item & $K w 1^{* \star}$ & SE (Kw1) & $z$ \\
\hline 45 & 0,6476 & 0,12114 & 5,34 \\
\hline 46 & 0,5270 & 0,12660 & 4,16 \\
\hline 47 & 0,7860 & 0,07196 & 10,92 \\
\hline 48 & 0,8380 & 0,08272 & 10,13 \\
\hline 49 & $* * *$ & & \\
\hline 50 & 0,8330 & 0,05574 & 14,94 \\
\hline 51 & 0,6645 & 0,10080 & 6,59 \\
\hline 52 & 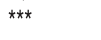 & & \\
\hline 53 & 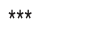 & & \\
\hline 54 & 0,8003 & 0,07994 & 10,01 \\
\hline 55 & 0,5914 & 0,10751 & 5,50 \\
\hline 56 & 0,7162 & 0,07940 & 9,02 \\
\hline 57 & 0,6991 & 0,09094 & 7,68 \\
\hline 58 & 0,7501 & 0,07937 & 9,45 \\
\hline 59 & 0,6960 & 0,09324 & 7,46 \\
\hline 60 & $\star \star \star$ & & \\
\hline 61 & 0,07701 & 5,94 & 0,7136 \\
\hline 62 & 0,07654 & 5,94 & 0,6502 \\
\hline 63 & 0,07736 & 5,32 & 0,6168 \\
\hline 64 & 0,08874 & 5,82 & 0,5705 \\
\hline 65 & 0,08874 & 5,99 & 0,7184 \\
\hline 66 & 0,07691 & 5,62 & 0,6784 \\
\hline 67 & 0,08874 & 6,61 & 0,8299 \\
\hline 68 & 0,08860 & 3,62 & 0,6110 \\
\hline 69 & 0,08127 & 7,23 & 0,7293 \\
\hline 70 & 0,09501 & 5,95 & 0,5962 \\
\hline 71 & 0,07783 & 4,28 & 0,4788 \\
\hline 72 & 0,08042 & 7,03 & 0,4998 \\
\hline 73 & 0,08139 & 5,26 & 0,7474 \\
\hline 74 & 0,08129 & 4,71 & 0,8696 \\
\hline 75 & 0,07565 & 7,87 & 0,5697 \\
\hline 76 & 0,07809 & 4,97 & 0,7096 \\
\hline 77 & 0,08047 & 4,42 & 0,4925 \\
\hline 78 & 0,08105 & 5,12 & 0,6891 \\
\hline 79 & 0,08062 & 8,50 & 0,8786 \\
\hline 80 & 0,07822 & 4,16 & 0,6015 \\
\hline 81 & 0,07681 & 3,76 & 0,4624 \\
\hline 82 & 0,08132 & 6,47 & 0,7968 \\
\hline 83 & $* * *$ & & \\
\hline 84 & 0,08358 & 5,23 & 0,3880 \\
\hline 85 & $* \star *$ & & \\
\hline 86 & 0,07589 & 5,89 & 0,6877 \\
\hline 87 & 0,08129 & 6,83 & 0,6022 \\
\hline 88 & 0,07801 & 4,73 & 0,7564 \\
\hline
\end{tabular}

* Programa kappa = Stephen Walter - Departamento de Epidemiologia Clínica e Bioestatística,

McMaster University, Canadá, 1990.

** Kappa ponderado.

*** Kappa não aplicável devido à ausência de categorias. 
através da decisão de substituir algum vocábulo referente a atividades mais comuns na cultura de origem do instrumento não por seu sinônimo, mas, por analogia, com o habitual na culturaalvo. Foi este o caso, por exemplo, da substituição, em nosso questionário, de woodwork por "trabalhos manuais". Este nos parece ser também o caso da tradução, por exemplo, do verbo modal can por "conseguir", ao invés de "poder" ou "ser capaz", os quais, embora talvez mais precisos, nos pareceram menos usuais em nosso meio. Achamos ainda importante sugerir que a mesma consideração se faça em relação ao uso do presente simples em português para traduzir o presente contínuo ou o gerúndio do inglês.

Pudemos ainda, por exemplo, verificar a observação de Sechrest ${ }^{20}$ de que muitas vezes é mais importante explicar o significado de uma palavra ou expressão do que tentar parear vocábulos sinônimos sem considerar seu uso contextual e/ou cultural. Em nosso estudo, percebemos que, em línguas menos concisas, como o caso do português em relação ao inglês, talvez seja melhor sacrificar a concisão da tradução em benefício da compreensão.

Ainda com relação a esse aspecto, consideramos interessante comentar um fato pitoresco ocorrido durante a aplicação, quando um sujeito perguntou se a palavra "palhaço" no item 34 era no sentido de "engraçado" ou de "bobo". Pudemos perceber então que, apesar de todos os cuidados tomados ao longo do processo, ainda havia passado despercebido um viés contextual, uma vez que a palavra clown do original permite as duas possibilidades apontadas no exemplo. Mais uma vez, deve-se apontar que a tradução deve ser um processo dinâmico, constantemente reavaliado e reexaminado.

Finalmente, em um aspecto global, podemos dizer que nos surpreendeu o pequeno

Tabela 4 - Coeficiente de correlação de Cohen (kappa) para escores sujeito por sujeito nas duas versões do Defense Style Questionnaire

\begin{tabular}{llll}
\hline Sujeito & KW1** & SE (KW1) & $\mathbf{Z}$ \\
\hline 1 & 0,6716 & 0,07033 & 9,54 \\
2 & 0,5062 & 0,10148 & 4,98 \\
3 & 0,7742 & 0,05917 & 13,08 \\
4 & 0,8486 & 0,03693 & 22,97 \\
5 & 0,9076 & 0,02413 & 37,61 \\
6 & 0,6490 & 0,07991 & 8,12 \\
7 & 0,7909 & 0,04878 & 16,21 \\
8 & 0,5255 & 0,08076 & 6,50 \\
9 & $* * *$ & & \\
10 & 0,6131 & 0,09145 & 6,70 \\
11 & 0,7603 & 0,05256 & 14,46 \\
12 & 0,5356 & 0,08391 & 6,38 \\
13 & 0,6509 & 0,07021 & 9,27 \\
14 & 0,4979 & 0,08644 & 5,76 \\
15 & 0,9868 & 0,00463 & 213,13 \\
16 & 0,8980 & 0,04915 & 18,27 \\
17 & $* * *$ & & \\
18 & 0,9908 & 0,00710 & 139,54 \\
19 & 0,9512 & 0,04327 & 21,98 \\
20 & 0,9991 & 0,00091 & 1097,91 \\
21 & 0,6658 & 0,07133 & 9,33 \\
22 & 0,4856 & 0,09766 & 4,97 \\
23 & 0,4409 & 0,10259 & 4,29 \\
24 & 0,7484 & 0,07505 & 9,97 \\
25 & 0,6802 & 0,08082 & 8,48 \\
\hline
\end{tabular}

\begin{tabular}{llll}
\hline Sujeito & KW1** & SE (KW1) & Z \\
\hline 26 & 0,6660 & 0,06759 & 9,85 \\
27 & 0,7632 & 0,05398 & 14,13 \\
28 & 0,6471 & 0,06985 & 9,26 \\
29 & $0,4 *$ & & \\
30 & 0,9267 & 0,02554 & 36,28 \\
31 & 0,6668 & 0,06887 & 9,68 \\
32 & 0,7477 & 0,05977 & 12,50 \\
33 & 0,7126 & 0,05884 & 12,19 \\
34 & 0,6275 & 0,07962 & 7,88 \\
35 & 0,4561 & 0,09164 & 4,97 \\
36 & 0,5964 & 0,07654 & 7,79 \\
37 & 0,7250 & 0,06800 & 10,66 \\
38 & 0,5921 & 0,08484 & 6,97 \\
39 & 0,5734 & 0,07811 & 7,34 \\
40 & 0,5225 & 0,08725 & 5,98 \\
41 & 0,6871 & 0,06860 & 10,01 \\
42 & 0,9508 & 0,03745 & 25,38 \\
43 & 0,9948 & 0,00363 & 273,88 \\
44 & $* * *$ & & \\
45 & 0,9991 & 0,00094 & 1062,87 \\
46 & 0,9877 & 0,01213 & 81,42 \\
47 & 0,9964 & 0,00259 & 384,71 \\
48 & 0,9992 & 0,00076 & 1314,73 \\
49 & 1,000 & 0 & \\
50 & 1,000 & 0 & \\
51 & 0,9766 & 0,02247 & 43,46 \\
\hline
\end{tabular}

* Programa kappa = Stephen Walter - Departamento de Epidemiologia Clínica e Bioestatística,

McMaster University, Canadá, 1990.

${ }^{* *}$ Kappa ponderado.

*** Kappa não aplicável devido à ausência de categorias. 
número de publicações relativas aos problemas de tradução de instrumentos de avaliação psiquiátrica para o português. Garyfallos ${ }^{23}$ relata a mesma surpresa em relação à sua língua materna, o grego, ressaltando a importância dos cuidados com os procedimentos de tradução e adaptação, assim como com o estudo da fidedignidade do instrumento traduzido. Esse mesmo autor lembra ainda que "palavras e expressões são, na verdade, símbolos que condensam um conjunto distintivo de significados, uma rede semântica específica de uma cultura. Logo, o conceito cultural desempenha um papel significativo que faz com que as diferenças culturais aportem problemas para a tradução e padronização de testes e instrumentos que tornam este procedimento muito complexo".

O trabalho de Blaya et al., por exemplo, faz a retrotradução e estuda a validade de conteúdo da versão reduzida do DSQ. Acreditamos que o estudo da validade de conteúdo, associado ao estudo de fidedignidade e às reflexões lingüísticas aqui apresentadas, pode representar uma contribuição significativa ao desenvolvimento de melhores versões do DSQ a serem usadas no Brasil. De nossa parte, consideramos que a complexidade dos procedimentos de tradução e adaptação de testes deve ser enfrentada, estudada e compartilhada, para que se possa promover um maior intercâmbio no uso de testes e instrumentos de avaliação de uma cultura para outra.

\section{O estudo da confiabilidade}

A análise estatística descritiva dos resultados revelou que, entre os itens não respondidos, as questões de número 17 e 84 apresentaram um maior grau de abstenção à resposta. Pensamos que é possível atribuir essa abstenção a dificuldades na compreensão do texto em inglês, que apresenta expressões idiomáticas em ambas as afirmativas em questão. Esse resultado poderia indicar, ainda, a necessidade de se reestruturar a afirmativa 84; talvez a expressão "me ocupo de uma tarefa" seja mais clara do que "me apego a uma tarefa". Consideramos, entretanto, que o nível de abstenção, apesar de ser o mais alto da amostra, ainda pode ser considerado aceitável, pois está bem abaixo dos $5 \%$ considerados como limite.

Para analisar a taxa de concordância entre as respostas atribuídas a cada questão em cada língua, trabalhamos com duas faixas. Abaixo de afirmativas 5 (39\%), 13 (33\%) e 81 (37\%). Acima de $80 \%$ de concordância, encontramos as afirmativas 60 (94\%), 79 (83\%) e 85 (92\%). A afirmativa 5 , além de apresentar uma expressão idiomática, sofreu uma modificação de conteúdo ao ser traduzida (trabalhos manuais para traduzir woodwork). As afirmativas 13 e 81 contêm palavras pouco usuais, facilmente identificadas como especialmente difíceis para nativos brasileiros, o que pode ter gerado problemas de compreensão. $O$ item 60 refere-se a um grave sintoma psicótico, com baixa probabilidade de aparecer em uma amostra de sujeitos normais e cujo aspecto bizarro tenderia a induzir certeza e intensidade na discordância. Os itens 79 e 85 dizem respeito ao uso de drogas, medicamentos e tabaco, cujo estigma social pode também ter gerado certeza e veemência na assertividade da resposta em ambas as versões. Essas características das afirmativas podem ter contribuído para elevar o índice de concordância. Vale ainda lembrar que, em uma escala de tipo Likert, com um amplo espectro (nove categorias) no grau de intensidade da concordância ou discordância, pequenas diferenças não podem ser consideradas significativas, o que fica demonstrado pela significância dos testes estatísticos. Neste caso específico, pelas diferenças entre os escores, em cada uma das versões, do teste $t$. Garyfallos ${ }^{23}$ comenta que essas pequenas diferenças podem inclusive ocorrer nos resultados de um mesmo teste, aplicado aos mesmos sujeitos em duas ocasiões diferentes ${ }^{23,27}$.

No teste de kappa, encontramos significância estatística para todas as correlações de todos os itens, o que corrobora a equivalência da tradução. Ao analisar a correlação entre as respostas de cada sujeito, encontramos três resultados não significantes, - que provavelmente indica um menor conhecimento da língua inglesa em relação aos demais componentes da amostra.

Quanto à consistência interna do instrumento, pode-se afirmar que os índices foram altamente satisfatórios. Tendo-se em vista que a literatura disponível $\left.\right|^{22,28}$ aponta como desejável um limite de $\alpha=0,60$, lembramos que obtivemos $\alpha=0,88$ para a forma original e $\alpha=0,91$ para a versão portuguesa.

Inúmeros autores ${ }^{20,22,24,27}$ vêm tentando definir diretrizes e construir teorias para a tradução transcultural de instrumentos de avaliação psiquiátrica ou psicológica. O quadro 1 é uma tentativa de reunir todos esses enfoques encontrados na literatura, uma vez que nos esforçamos para levar em 
consideração todas as dimensões sugeridas no presente trabalho.

Esse conjunto de resultados permite-nos concluir que há equivalência da tradução, sendo que o instrumento traduzido apresenta confiabilidade estatística para ser aplicado em nosso meio. Acreditamos que este estudo deve ser visto como um passo inicial no sentido do desenvolvimento da versão do DSQ em português (Anexo 1), uma vez que amostras maiores devem ser testadas e novos estudos de validade devem ser realizados.

Quadro 1 - Princípios básicos de tradução

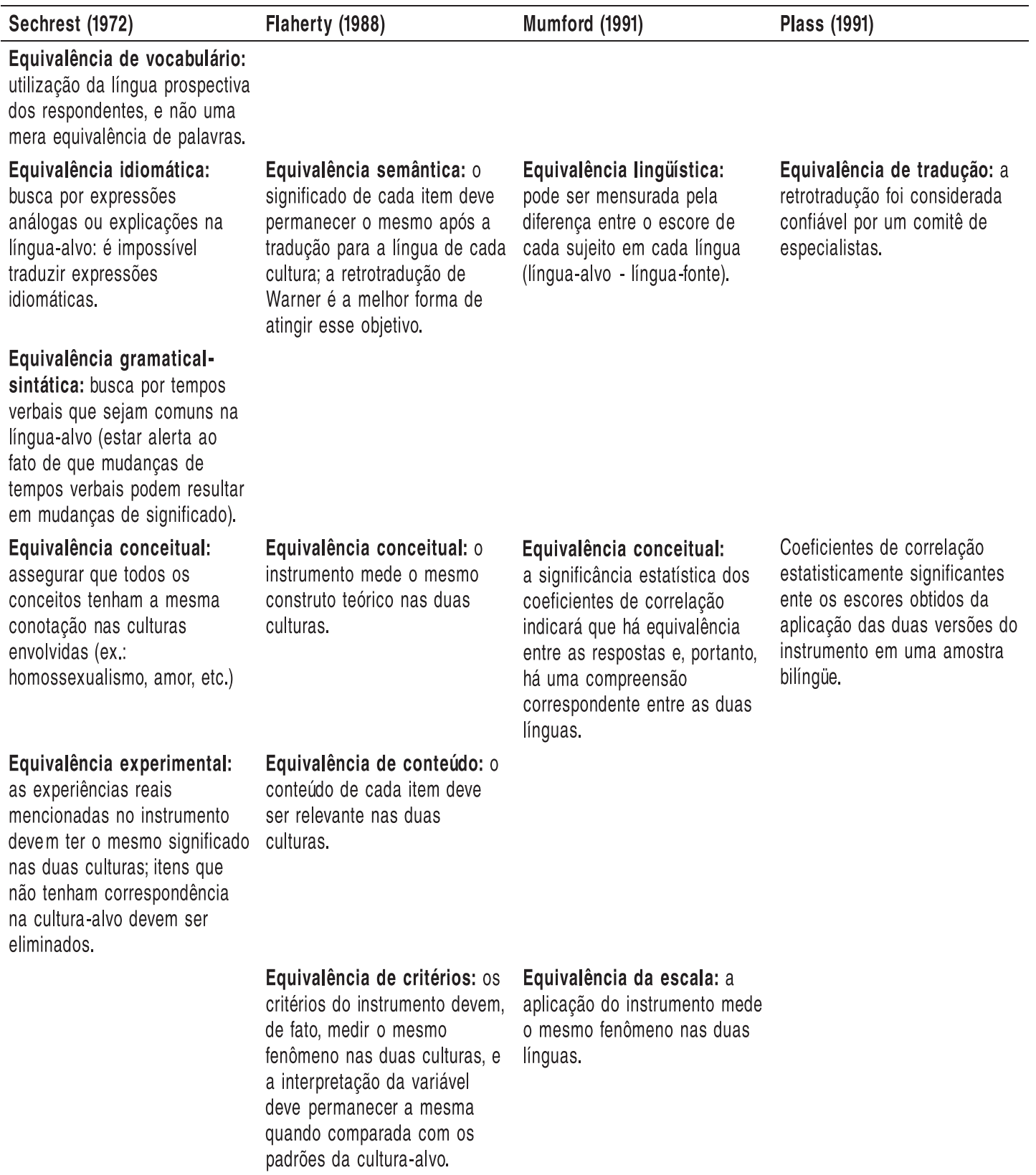




\section{Anexo 1 - Questionário para estilos de defesa (DSQ) de Bond, versão de 1984}

\section{INSTRUÇÕES}

Este questionário consiste em 88 afirmativas, cada uma seguida de uma escala de pontuação: $\begin{array}{lllllllllll}\text { Discordo inteiramente } & 1 & 2 & 3 & 4 & 5 & 6 & 7 & 8 & 9 & \text { Concordo inteiramente }\end{array}$ Assinale o seu grau de concordância, ou discordância, em relação a cada afirmativa e circule o número de pontos, de 1 a 9 , na linha abaixo da afirmativa.

Exemplo:

Montreal é uma cidade do Canadá

$\begin{array}{lllllllllll}\text { Discordo inteiramente } & 1 & 2 & 3 & 4 & 5 & 6 & 7 & 8 & 9 & \text { Concordo inteiramente }\end{array}$ Você escolheria o 9 e circularia o 9 na linha abaixo da afirmativa.

1. Fico satisfeito ajudando os outros e se fosse impedido de fazer isto eu ficaria deprimido.

$\begin{array}{lllllllllll}\text { Discordo inteiramente } & 1 & 2 & 3 & 4 & 5 & 6 & 7 & 8 & 9 & \text { Concordo inteiramente }\end{array}$

2. Freqüentemente as pessoas me chamam de emburrado.

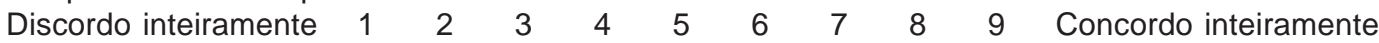

3. Consigo manter um problema fora de minha mente, até que tenha tempo de lidar com ele. $\begin{array}{lllllllllll}\text { Discordo inteiramente } & 1 & 2 & 3 & 4 & 5 & 6 & 7 & 8 & 9 & \text { Concordo inteiramente }\end{array}$

4. Sou sempre tratado injustamente.

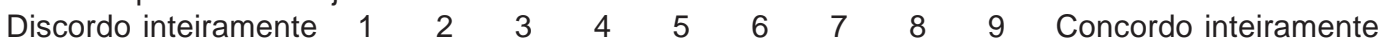

5. Lido satisfatoriamente com minha ansiedade fazendo alguma coisa construtiva e criativa, como pintar ou fazer trabalhos manuais.

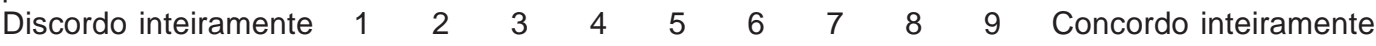

6. De vez em quando deixo para amanhã o que deveria fazer hoje.

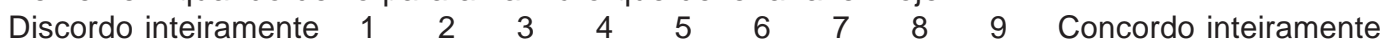

7. Estou sempre me metendo no mesmo tipo de situações frustrantes e não sei por que.

$\begin{array}{lllllllllll}\text { Discordo inteiramente } & 1 & 2 & 3 & 4 & 5 & 6 & 7 & 8 & 9 & \text { Concordo inteiramente }\end{array}$

8. Sou capaz de rir de mim mesmo com bastante facilidade.

$\begin{array}{lllllllllll}\text { Discordo inteiramente } & 1 & 2 & 3 & 4 & 5 & 6 & 7 & 8 & 9 & \text { Concordo inteiramente }\end{array}$

9. Ajo como uma criança, quando estou frustrado.

$\begin{array}{lllllllllll}\text { Discordo inteiramente } & 1 & 2 & 3 & 4 & 5 & 6 & 7 & 8 & 9 & \text { Concordo inteiramente }\end{array}$

10. Sou muito tímido no que diz respeito a defender meus direitos perante as pessoas.

$\begin{array}{lllllllllll}\text { Discordo inteiramente } & 1 & 2 & 3 & 4 & 5 & 6 & 7 & 8 & 9 & \text { Concordo inteiramente }\end{array}$

11. Sou superior à maioria das pessoas que conheço.

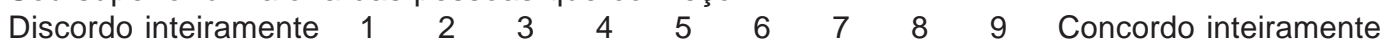

12. As pessoas tendem a maltratar-me.

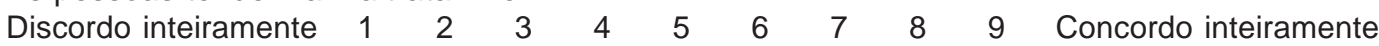

13. Se alguém me assaltasse e roubasse meu dinheiro, pensaria que ele precisaria, antes, ser ajudado, do que punido.

$\begin{array}{lllllllllll}\text { Discordo inteiramente } & 1 & 2 & 3 & 4 & 5 & 6 & 7 & 8 & 9 & \text { Concordo inteiramente }\end{array}$

14. De vez em quando penso em coisas muito ruins para falar a respeito delas.

$\begin{array}{lllllllllll}\text { Discordo inteiramente } & 1 & 2 & 3 & 4 & 5 & 6 & 7 & 8 & 9 & \text { Concordo inteiramente }\end{array}$

15. De vez em quando eu rio de uma piada suja.

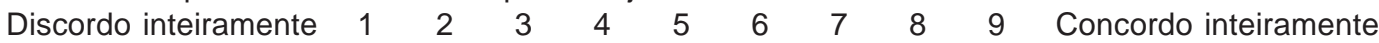

16. As pessoas dizem que eu me pareço com uma avestruz, com minha cabeça enterrada na areia. Em outras palavras, inclino-me a ignorar fatos desagradáveis, como se eles não existissem.
Discordo inteiramente
$2 \quad 3 \quad 4$
56
89
Concordo inteiramente 
17. Não me permito dar o máximo de mim em uma competição.

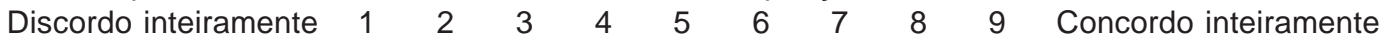

18. Freqüentemente, sinto-me superior às pessoas que estão comigo. $\begin{array}{lllllllllll}\text { Discordo inteiramente } & 1 & 2 & 3 & 4 & 5 & 6 & 7 & 8 & 9 & \text { Concordo inteiramente }\end{array}$

19. Alguém está roubando tudo que obtenho emocionalmente.

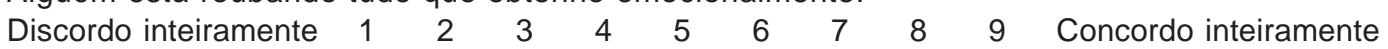

20. Às vezes fico com raiva. $\begin{array}{lllllllllll}\text { Discordo inteiramente } & 1 & 2 & 3 & 4 & 5 & 6 & 7 & 8 & 9 & \text { Concordo inteiramente }\end{array}$

21. Freqüentemente, sou levado a agir impulsivamente. $\begin{array}{lllllllllll}\text { Discordo inteiramente } & 1 & 2 & 3 & 4 & 5 & 6 & 7 & 8 & 9 & \text { Concordo inteiramente }\end{array}$

22. Prefiro, antes, passar fome, do que ser forçado a comer. $\begin{array}{lllllllllll}\text { Discordo inteiramente } & 1 & 2 & 3 & 4 & 5 & 6 & 7 & 8 & 9 & \text { Concordo inteiramente }\end{array}$

23. Ignoro o perigo como se eu fosse o Super-homem. Discordo inteiramente $\begin{array}{lllllllllll}1 & 2 & 3 & 4 & 5 & 6 & 7 & 8 & 9 & \text { Concordo inteiramente }\end{array}$

24. Orgulho-me de minha habilidade em colocar as pessoas em seus devidos lugares. Discordo inteiramente $\begin{array}{lllllllllll}1 & 2 & 3 & 4 & 5 & 6 & 7 & 8 & 9 & \text { Concordo inteiramente }\end{array}$

25. As pessoas dizem-me que tenho complexo de perseguição. Discordo inteiramente $\begin{array}{lllllllllll} & 1 & 2 & 3 & 4 & 5 & 6 & 7 & 8 & 9 & \text { Concordo inteiramente }\end{array}$

26. Às vezes, quando não estou me sentido bem, fico de cara feia. $\begin{array}{lllllllllll}\text { Discordo inteiramente } & 1 & 2 & 3 & 4 & 5 & 6 & 7 & 8 & 9 & \text { Concordo inteiramente }\end{array}$

27. Freqüentemente, ajo impulsivamente, quando alguma coisa está me aborrecendo. $\begin{array}{lllllllllll}\text { Discordo inteiramente } & 1 & 2 & 3 & 4 & 5 & 6 & 7 & 8 & 9 & \text { Concordo inteiramente }\end{array}$

28. Fico fisicamente doente, quando as coisas não estão indo bem para mim. $\begin{array}{lllllllllll}\text { Discordo inteiramente } & 1 & 2 & 3 & 4 & 5 & 6 & 7 & 8 & 9 & \text { Concordo inteiramente }\end{array}$

29. Sou uma pessoa muito inibida. $\begin{array}{lllllllllll}\text { Discordo inteiramente } & 1 & 2 & 3 & 4 & 5 & 6 & 7 & 8 & 9 & \text { Concordo inteiramente }\end{array}$

30. Sou um verdadeiro artista não reconhecido. $\begin{array}{lllllllllll}\text { Discordo inteiramente } & 1 & 2 & 3 & 4 & 5 & 6 & 7 & 8 & 9 & \text { Concordo inteiramente }\end{array}$

31. Nem sempre digo a verdade. $\begin{array}{lllllllllll}\text { Discordo inteiramente } & 1 & 2 & 3 & 4 & 5 & 6 & 7 & 8 & 9 & \text { Concordo inteiramente }\end{array}$

32. Afasto-me das pessoas, quando me sinto magoado. $\begin{array}{lllllllllll}\text { Discordo inteiramente } & 1 & 2 & 3 & 4 & 5 & 6 & 7 & 8 & 9 & \text { Concordo inteiramente }\end{array}$

33. Às vezes, avanço tanto, que as outras pessoas precisam colocar limites para mim. $\begin{array}{lllllllllll}\text { Discordo inteiramente } & 1 & 2 & 3 & 4 & 5 & 6 & 7 & 8 & 9 & \text { Concordo inteiramente }\end{array}$

34. Meus amigos vêem-me como um palhaço. $\begin{array}{llllllllllll}\text { Discordo inteiramente } & 1 & 2 & 3 & 4 & 5 & 6 & 7 & 8 & 9 & \text { Concordo inteiramente }\end{array}$

35. Quando estou com raiva eu me afasto das pessoas. $\begin{array}{llllllllllll}\text { Discordo inteiramente } & 1 & 2 & 3 & 4 & 5 & 6 & 7 & 8 & 9 & \text { Concordo inteiramente }\end{array}$

36. Tenho tendência a ficar com um pé atrás com pessoas que se mostram mais amigáveis do que eu esperaria.

$\begin{array}{lllllllllll}\text { Discordo inteiramente } & 1 & 2 & 3 & 4 & 5 & 6 & 7 & 8 & 9 & \text { Concordo inteiramente }\end{array}$

37. Tenho talentos especiais que me permitem levar a vida sem problemas. $\begin{array}{lllllllllll}\text { Discordo inteiramente } & 1 & 2 & 3 & 4 & 5 & 6 & 7 & 8 & 9 & \text { Concordo inteiramente }\end{array}$

38. Às vezes, em eleições, voto em pessoas sobre as quais sei muito pouco. $\begin{array}{lllllllllll}\text { Discordo inteiramente } & 1 & 2 & 3 & 4 & 5 & 6 & 7 & 8 & 9 & \text { Concordo inteiramente }\end{array}$ 
39. Freqüentemente, atraso-me para compromissos.

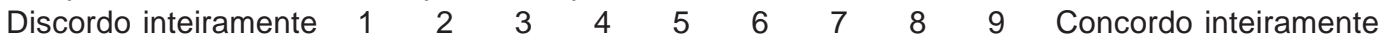

40. Resolvo mais coisas em meus devaneios, do que na vida real.

Discordo inteiramente $\begin{array}{lllllllllll}1 & 2 & 3 & 4 & 5 & 6 & 7 & 8 & 9 & \text { Concordo inteiramente }\end{array}$

41. Sou muito tímido para aproximar-me das pessoas.

Discordo inteiramente $\begin{array}{llllllllll}1 & 2 & 3 & 4 & 5 & 6 & 7 & 8 & 9 & \text { Concordo inteiramente }\end{array}$

42. Não tenho medo de nada.

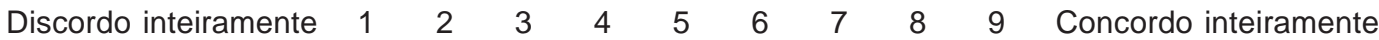

43. Às vezes, penso que sou um anjo e, em outras, que sou um demônio.

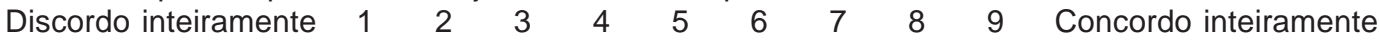

44. No jogo, prefiro ganhar do que perder.

$\begin{array}{lllllllllll}\text { Discordo inteiramente } & 1 & 2 & 3 & 4 & 5 & 6 & 7 & 8 & 9 & \text { Concordo inteiramente }\end{array}$

45. Fico muito sarcástico quando estou com raiva.

Discordo inteiramente $\begin{array}{lllllllllll}1 & 2 & 3 & 4 & 5 & 6 & 7 & 8 & 9 & \text { Concordo inteiramente }\end{array}$

46. Fico abertamente agressivo, quando me sinto magoado.

Discordo inteiramente $\begin{array}{llllllllll}1 & 2 & 3 & 4 & 5 & 6 & 7 & 8 & 9 & \text { Concordo inteiramente }\end{array}$

47. Acredito que devo dar a outra face, quando alguém me magoa.

Discordo inteiramente $\begin{array}{lllllllllll}1 & 2 & 3 & 4 & 5 & 6 & 7 & 8 & 9 & \text { Concordo inteiramente }\end{array}$

48. Não leio todo os editoriais, num jornal, todos os dias.

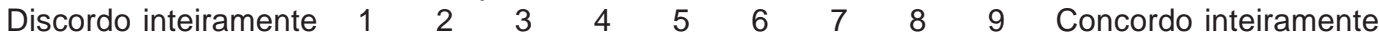

49. Quando estou triste, afasto-me das pessoas.

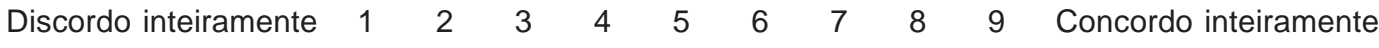

50. Sou tímido em relação ao sexo.

Discordo inteiramente $\begin{array}{ccccccccccc}1 & 2 & 3 & 4 & 5 & 6 & 7 & 8 & 9 & \text { Concordo inteiramente }\end{array}$

51. Sempre sinto que algum dos meus conhecidos é como um anjo da guarda.

Discordo inteiramente $\begin{array}{lllllllllll}1 & 2 & 3 & 4 & 5 & 6 & 7 & 8 & 9 & \text { Concordo inteiramente }\end{array}$

52. Minha filosofia é "não ouvir o mal, não fazer o mal, não ver o mal".

Discordo inteiramente $\begin{array}{lllllllllll}1 & 2 & 3 & 4 & 5 & 6 & 7 & 8 & 9 & \text { Concordo inteiramente }\end{array}$

53. No que me diz respeito, as pessoas são ou boas, ou más.

Discordo inteiramente $\begin{array}{lllllllllll}1 & 2 & 3 & 4 & 5 & 6 & 7 & 8 & 9 & \text { Concordo inteiramente }\end{array}$

54. Se meu chefe me incomodasse, eu seria capaz de cometer um erro em meu serviço, ou trabalhar mais devagar, para descontar nele.

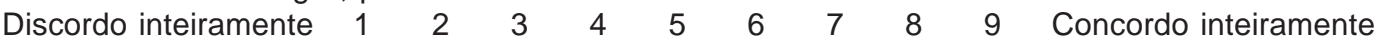

55. Todos estão contra mim.

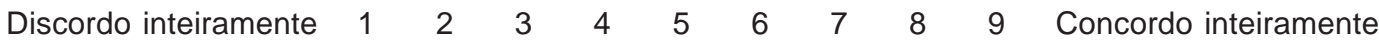

56. Tento ser agradável com as pessoas de quem não gosto.

Discordo inteiramente $\begin{array}{lllllllllll}1 & 2 & 3 & 4 & 5 & 6 & 7 & 8 & 9 & \text { Concordo inteiramente }\end{array}$

57. Ficaria muito nervoso, se um avião em que estivesse voando perdesse uma turbina.

Discordo inteiramente $\begin{array}{lllllllllll}1 & 2 & 3 & 4 & 5 & 6 & 7 & 8 & 9 & \text { Concordo inteiramente }\end{array}$

58. Conheço alguém que é capaz de ser justo e imparcial, em qualquer coisa que faça.

Discordo inteiramente $\begin{array}{lllllllllll}1 & 2 & 3 & 4 & 5 & 6 & 7 & 8 & 9 & \text { Concordo inteiramente }\end{array}$

59. Consigo abafar meus sentimentos, para evitar que eles interfiram no que estou fazendo, caso eu os deixasse escapar.

$\begin{array}{lllllllllll}\text { Discordo inteiramente } & 1 & 2 & 3 & 4 & 5 & 6 & 7 & 8 & 9 & \text { Concordo inteiramente }\end{array}$

60. Algumas pessoas estão tramando matar-me.

$\begin{array}{lllllllllll}\text { Discordo inteiramente } & 1 & 2 & 3 & 4 & 5 & 6 & 7 & 8 & 9 & \text { Concordo inteiramente }\end{array}$ 
61. Geralmente, sou capaz de ver o lado cômico de situações desagradáveis e penosas. $\begin{array}{lllllllllll}\text { Discordo inteiramente } & 1 & 2 & 3 & 4 & 5 & 6 & 7 & 8 & 9 & \text { Concordo inteiramente }\end{array}$

62. Fico com dor de cabeça, quando tenho que fazer algo de que não gosto. $\begin{array}{lllllllllll}\text { Discordo inteiramente } & 1 & 2 & 3 & 4 & 5 & 6 & 7 & 8 & 9 & \text { Concordo inteiramente }\end{array}$

63. Freqüentemente, me dou conta de que estou sendo muito agradável com pessoas das quais eu teria todo o direito de ter raiva.

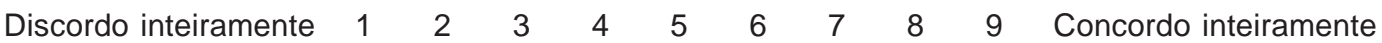

64. Não existe isto de que todo mundo "tem algo de bom". Se você é mau, é totalmente mau". Discordo inteiramente $\begin{array}{lllllllllll}1 & 2 & 3 & 4 & 5 & 6 & 7 & 8 & 9 & \text { Concordo inteiramente }\end{array}$

65. Não deveríamos, nunca, ficar com raiva de pessoas de quem não gostamos. $\begin{array}{lllllllllll}\text { Discordo inteiramente } & 1 & 2 & 3 & 4 & 5 & 6 & 7 & 8 & 9 & \text { Concordo inteiramente }\end{array}$

66. Tenho a certeza de que a vida maltrata-me.

$\begin{array}{llllllllllll}\text { Discordo inteiramente } & 1 & 2 & 3 & 4 & 5 & 6 & 7 & 8 & 9 & \text { Concordo inteiramente }\end{array}$

67. Eu desmorono em situações de estresse. $\begin{array}{lllllllllll}\text { Discordo inteiramente } & 1 & 2 & 3 & 4 & 5 & 6 & 7 & 8 & 9 & \text { Concordo inteiramente }\end{array}$

68. Quando sei que terei que me defrontar com uma situação difícil, como um exame, ou uma entrevista para emprego, tento imaginar como vai ser e planejo um jeito de enfrentá-la.

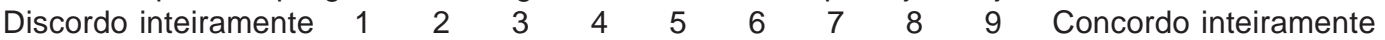

69. Os médicos nunca entendem, realmente, o que está errado comigo. $\begin{array}{lllllllllll}\text { Discordo inteiramente } & 1 & 2 & 3 & 4 & 5 & 6 & 7 & 8 & 9 & \text { Concordo inteiramente }\end{array}$

70. Quando morre alguém próximo a mim eu não fico aborrecido. Discordo inteiramente $\begin{array}{lllllllllll} & 1 & 2 & 3 & 4 & 5 & 6 & 7 & 8 & 9 & \text { Concordo inteiramente }\end{array}$

71. Depois que brigo por meus direitos, inclino-me a desculpar-me por minha assertividade. $\begin{array}{lllllllllll}\text { Discordo inteiramente } & 1 & 2 & 3 & 4 & 5 & 6 & 7 & 8 & 9 & \text { Concordo inteiramente }\end{array}$

72. A maior parte das coisas que acontece comigo não é de minha responsabilidade. $\begin{array}{lllllllllll}\text { Discordo inteiramente } & 1 & 2 & 3 & 4 & 5 & 6 & 7 & 8 & 9 & \text { Concordo inteiramente }\end{array}$

73. Quando estou deprimido, ou ansioso, comer faz-me sentir melhor. Discordo inteiramente $\begin{array}{lllllllllll} & 1 & 2 & 3 & 4 & 5 & 6 & 7 & 8 & 9 & \text { Concordo inteiramente }\end{array}$

74. Trabalhar duro faz-me sentir melhor. $\begin{array}{lllllllllll}\text { Discordo inteiramente } & 1 & 2 & 3 & 4 & 5 & 6 & 7 & 8 & 9 & \text { Concordo inteiramente }\end{array}$

75. Meus médicos não são capazes de ajudar-me, realmente, a resolver meus problemas. $\begin{array}{lllllllllll}\text { Discordo inteiramente } & 1 & 2 & 3 & 4 & 5 & 6 & 7 & 8 & 9 & \text { Concordo inteiramente }\end{array}$

76. Sempre me dizem que não demonstro meus sentimentos. $\begin{array}{lllllllllll}\text { Discordo inteiramente } & 1 & 2 & 3 & 4 & 5 & 6 & 7 & 8 & 9 & \text { Concordo inteiramente }\end{array}$

77. Sempre acho que as pessoas percebem mais significados em filmes, peças, ou livros, do que realmente há para ser visto.

$\begin{array}{lllllllllll}\text { Discordo inteiramente } & 1 & 2 & 3 & 4 & 5 & 6 & 7 & 8 & 9 & \text { Concordo inteiramente }\end{array}$

78. Tenho hábitos e rituais que me sinto impelido a realizar, senão algo terrível acontecerá. $\begin{array}{lllllllllll}\text { Discordo inteiramente } & 1 & 2 & 3 & 4 & 5 & 6 & 7 & 8 & 9 & \text { Concordo inteiramente }\end{array}$

79. Quando estou tenso, uso drogas, medicamentos ou bebidas alcoólicas. $\begin{array}{lllllllllll}\text { Discordo inteiramente } & 1 & 2 & 3 & 4 & 5 & 6 & 7 & 8 & 9 & \text { Concordo inteiramente }\end{array}$

80. Quando me sinto mal, tento procurar alguém. $\begin{array}{lllllllllll}\text { Discordo inteiramente } & 1 & 2 & 3 & 4 & 5 & 6 & 7 & 8 & 9 & \text { Concordo inteiramente }\end{array}$

81. Se consigo prever com antecedência que vou ficar triste, consigo lidar melhor com meus sentimentos.

$\begin{array}{lllllllllll}\text { Discordo inteiramente } & 1 & 2 & 3 & 4 & 5 & 6 & 7 & 8 & 9 & \text { Concordo inteiramente }\end{array}$ 
82. Não importa o quanto eu reclame, nunca obtenho uma resposta satisfatória.

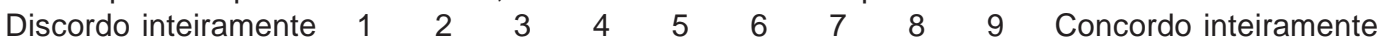

83. Freqüentemente, descubro que não sinto nada, quando a situação pareceria justificar fortes emoções.

$\begin{array}{lllllllllll}\text { Discordo inteiramente } & 1 & 2 & 3 & 4 & 5 & 6 & 7 & 8 & 9 & \text { Concordo inteiramente }\end{array}$

84. Se me ocupo com alguma tarefa disponível, evito a depressão, ou a ansiedade.

$\begin{array}{lllllllllll}\text { Discordo inteiramente } & 1 & 2 & 3 & 4 & 5 & 6 & 7 & 8 & 9 & \text { Concordo inteiramente }\end{array}$

85. Fumo, quando estou nervoso.

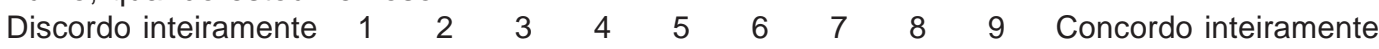

86. Se estivesse em uma crise, procuraria por outra pessoa que já teve o mesmo problema.

$\begin{array}{lllllllllll}\text { Discordo inteiramente } & 1 & 2 & 3 & 4 & 5 & 6 & 7 & 8 & 9 & \text { Concordo inteiramente }\end{array}$

87. Não posso ser culpado pelo que faço de errado.

$\begin{array}{lllllllllll}\text { Discordo inteiramente } & 1 & 2 & 3 & 4 & 5 & 6 & 7 & 8 & 9 & \text { Concordo inteiramente }\end{array}$

88. Se tenho um pensamento agressivo, sinto necessidade de fazer algo para compensá-lo.

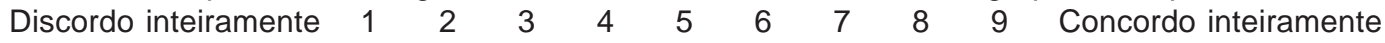




\section{REFERÊNCIAS}

1. Bond M. Manual for the defense style questionnaire. Sir Mortimer B. Davis-Jewish General Hospital, Department of Psychiatry. Montreal: Canada. 1991. [mimeographed by the author].

2. Freud S. As neuropsicoses de defesa. Rio de Janeiro: Imago; 1977.

3. Vaillant GE. Ego mechanisms of defense. Washington, DC: American Psychiatric Press; 1992.

4. Bond M, Gardner S, Christian J, Sigal J. Empirical study of self-rated defense styles. Arch Gen Psychiatry. 1983;40(3):333-8.

5. Haan N. A tripartite model of ego functioning values and clinical and research applications. J Nerv Ment Dis. 1969;148(1):14-30.

6. Semrad EV, Grinspoon L, Fienberg SE. Development of an ego profile scale. Arch Gen Psychiatry. 1973;28(1):707.

7. Vaillant GE. Theoretical hierarchy of adaptive ego mechanisms: a 30 year follow-up of 30 men selected for psychological health. Arch Gen Psychiatry. 1971;24(2):107-18

8. Vaillant GE. Why men seek psychotherapy: results of a survey of college graduates. Am J Psychiatry. $1972 ; 129(6): 645-51$.

9. Vaillant GE. Natural history of male psychological health. II. Some antecedents of healthy adult adjustment. Arch Gen Psychiatry. 1974;31(1):15-22.

10. Vaillant GE. Natural history of male psychological health. III. Empirical dimensions of mental health. Arch Gen Psychiatry. 1975;32(4):420-6.

11. Vaillant GE. Natural history of male psychological health: $V$. The relation of choice of ego mechanisms of defense to adult adjustment. Arch Gen Psychiatry. 1976;33(5):535-45.

12. Vaillant GE, Bond M, Vaillant CO. An empirically validated hierarchy of defense mechanisms. Arch Gen Psychiatry. 1986;43(8):786-94

13. Bond M. An empirical study of defensive styles: the defense style questionnaire. In: Vaillant GE, ed. Ego mechanisms of defense. Washington: American Psychiatric Press; 1992. p. 127-58.

14. Pollock C, Andrews G. Defense styles associated with specific anxiety disorders. Am J. Psychiatry. 1989;146(11):1500-2.

15. Andrews $G$, Singh $M$, Bond $M$. The defense style questionnaire. J Nerv Ment Dis. 1993;181(4):246-56.

16. Andrade MPM. Tradução e adaptação do DSQ (Defense Style Questionnaire) para uso no Brasil [Dissertação]. São Paulo: Universidade Federal de São Paulo; 1996.

17. Blaya C, et al. Versão em português do Defense Style Questionnaire (DSQ-40) para avaliação dos mecanismos de defesa: um estudo preliminar. Rev Bras Psiquiatr. 2004;26(4):255-8.

18. Werner O, Campbell DT. Translating, working through interpreters, and the problem of decentering. In: Naroll R, Cohen R, eds. A handbook of method in cultural anthropology. New York: American Museum of Natural History; 1970. p. 398-420.

19. Brislin RW. Back translation for cross-cultural research. J Cross-Cultural Psychol. 1970;1(3):185-216.

20. Secherest L, Fay TL, Zaidi SMH. Problems of translation in cross-cultural research. J Cross-Cultural Psychol. 1972;3(1):41-56

21. Spielberger $C D$, Gorsuch RL, Lushene RE. Inventário de ansiedade traço-estado. Rio de Janeiro: CEPA; 1979.

22. Flaherty JA, Gaviria FM, Pathak D, Mitchell T, Wintrob R,
Richman JA, et al. Developing instruments for crosscultural psychiatric research. J Nerv Ment Dis. 1988;176(5):257-63.

23. Garyfallos G, Karastergiou A, Adamopoulou A, Moutzoukis C, Alagiozidou E, Mala D, et al. Greek version of the General Health Questionnaire accuracy of translation and validity. Acta Psychiatr Scand. 1991;84(4):371-8.

24. Plass AM. Adaptação para o português da escala de memória de Wechsler-revisada: fidedignidade e validade [Dissertação]. Porto Alegre: Universidade Federal do Rio Grande do Sul; 1991.

25. Carvalho FR, Lima MG, Azevedo RCS, Caetano D. Tradução do inglês para o português do questionário de auto-avaliação da escala de Hamilton para a depressão. J Bras Psiq. 1993;42(5):255-60.

26. Chan DW. The Chinese version of the general health questionnaire: does language make a difference? Psychol Med. 1985;15(1):147-55.

27. Mumford DB, Tareen IA, Bajwa MA, Bhatti MR, Karim R. The translation and evaluation of an Urdu version of the Hospital Anxiety and Depression Scale. Acta Psychiatr Scand. 1991;83(2):81-5.

28. Bartko JJ, Carpenter WT Jr. On the methods and theory of reliability. J Nerv Ment Dis. 1976;163(5):307-17.

29. Karno M, Burnam MA, Escobar JI, Hough RL, Eaton WW. The Spanish language version of the diagnostic interview schedule. In: Eaton WW, Kessler LG, eds. Epidemiology field methods in psychiatry. Washington: American Psychiatric Press; 1993. p. 171-90.

30. Cronbach LJ. Coefficient alpha and the internal structure of tests. Psychometrika. 1951;16(13):297-334.

31. De Figueiredo JM, Lemkau PV. Psychiatric interviewing across cultures: some problems and prospects. Soc Psychiatry. 1980;15:117-21.

32. Berkanovic E. The effect of inadequate language translation on Hispanics' responses to health surveys. Am J Public Health. 1980;70(12):1273-6.

\section{RESUMO}

O Defense Style Questionnaire (DSQ) é um instrumento para avaliação de derivados conscientes dos mecanismos de defesa do ego, desenvolvido e validado por Michael Bond em 1983 no Canadá. O presente trabalho consistiu da tradução e adaptação desse instrumento para o português, assim como do estudo de confiabilidade estatística da tradução em relação ao original.

Métodos: A tradução foi feita por um grupo de profissionais (psiquiatras, psicólogos e professores de inglês) segundo a técnica de retrotradução. $O$ estudo da confiabilidade da tradução foi realizado em uma amostra de 51 bilíngües (inglês/português), os quais responderam aos testes nas duas versões (original e traduzida). A análise estatística da consistência interna e das correlações item por item e sujeito por sujeito, assim como entre os escores médios de cada uma das formas (original e traduzida), demonstrou que as duas versões são equivalentes $e$, portanto, a tradução para o português é precisa. Foram ainda avaliadas as abstenções às respostas e a taxa de concordância entre as versões.

Resultados e conclusão: Todos os resultados foram bastante satisfatórios e estatisticamente 
significantes, o que nos permite concluir que o instrumento traduzido é adequado para uso no Brasil.

Palavras-chave: Tradução, confiabilidade, questionário, mecanismos de defesa do ego, DSQ.

\section{ABSTRACT}

The Defense Style Questionnaire (DSQ) is an instrument designed to measure conscious derivatives of ego defense mechanisms. It was developed and validated by Michael Bond in 1983 in Canada. This study presents a translation and adaptation of the $D S Q$ into Portuguese, as well as an evaluation of the statistical reliability of the Portuguese version compared to its original form.

Methods: The translation was carried out by a group of psychiatrists, psychologists and English teachers, using the back-translation technique. The reliability study was administered to a sample of 51 bilingual respondents (English/Portuguese), who performed the tests in both versions (original and translated). Statistical analysis of internal consistency and item by item and subject by subject correlations, as well as mean score between the two versions (original and translated) have demonstrated that both forms are equivalent; therefore, the translation into Portuguese is accurate. Agreement rate and unanswered items were also evaluated.

Results and conclusion: All results were quite satisfactory and statistically significant, which leads to the conclusion that the translated instrument is adequate for application in Brazil.

Keywords: Translation, reliability, questionnaire, ego defense mechanisms, DSQ.

Title: Brazilian version of Michael Bond's defense style questionnaire (DSQ): problems and achievements

Correspondência:

Mônica Andrade

Av. Nicomedes Alves dos Santos, 1854

CEP 38411-106

Uberlândia, MG

Tel./fax: (34) 3214.9710

E-mail: monica@netsite.com.br

Copyright (@) Revista de Psiquiatria

do Rio Grande do Sul - SPRS 